\title{
REABILITAÇÃO COM INSTALAÇÃO DE IMPLANTE IMEDIATO EM REGIÃO DE MOLAR COM ABORDAGEM ALTERNATIVA DE OSTEOTOMIA: RELATO DE CASO
}

\author{
REHABILITATION WITH IMMEDIATE IMPLANT PLACEMENT IN MOLAR REGION \\ USING AN ALTERNATIVE OSTEOTOMY APPROACH: A CASE REPORT
}

\author{
Sara Cristina de ARAÚJ01; Lorraine Caroline Ferreira de ASSIS'; Priscilla Cardoso LAZARI²; João Antônio Chaves de SOUZA; \\ Cláudio Rodrigues LELES 4 \\ 1 - Cirurgiã-dentista, Departamento de Reabilitação Oral, Faculdade de Odontologia, Universidade Federal de Goiás. \\ 2 - Professora Substituta da Faculdade de Odontologia, Departamento de Reabilitação Oral, Universidade Federal de Goiás. \\ 3 - Professor Adjunto de Periodontia da Faculdade de Odontologia, Departamento de Saúde Oral, Universidade Federal de Goiás. \\ 4 - Professor Titular da Faculdade de Odontologia, Departamento de Reabilitação Oral, Universidade Federal de Goiás.
}

\begin{abstract}
RESUMO
Objetivo: apresentar um caso clínico de instalação de implante imediato em região de bifurcação após exodontia de molar com uma técnica de osteotomia alternativa com o preparo do sitio implantar previamente à remoção das raízes. Materiais e métodos: em dezembro de 2017, JNPS, 39 anos de idade, sexo masculino, compareceu à Faculdade de Odontologia com queixa do dente 46 fraturado sem sintomatologia dolorosa. Nos exames clínicos e radiográficos o dente 46 apresentava tratamento endodôntico, sem remanescente coronário e amplo septo inter-radicular que favorecia a instalação de implante imediato. A cirurgia ocorreu em fevereiro de 2018 com o preparo do leito do implante na região do centro do dente previamente à exodontia. Em seguida foi realizada a extração das raízes de forma minimamente traumática, visando preservar a estrutura circundante. Foi utilizado um implante
\end{abstract}

Cone Morse 3,75x9mm (Titamax CM Cortical-Neodent, Curitiba, Brasil). O torque final de inserção foi de $20 \mathrm{~N} / \mathrm{cm}$ e foi instalado o cicatrizador para procedimento cirúrgico de 1 estágio. Após 4 meses foi instalado o pilar protético (Pilar CM - Neodent, Curitiba, Brasil) com altura de 2,5 mm e nas sessões seguintes foram realizados os procedimentos para confecção de coroa metalocerâmica. Resultados: no acompanhamento de 12 meses após instalação do implante, verificou-se aspectos clínicos e radiográficos de normalidade, além de satisfação do paciente com o tratamento. Conclusão: a técnica utilizada facilita o preparo do leito receptor e a instalação de implante em condições de estabilidade favorável, podendo ser empregada em situações clínicas semelhantes.

Palavras-chave: Implante dentário; Prótese dentária; Osteotomia.

\section{INTRODUÇÃO}

A instalação imediata de implantes pós-exodontia foi uma proposta de Schulte e Heimke ${ }^{1}$ (1976) e Schulte et al. ${ }^{2}$ (1978). Esta abordagem é uma alternativa que tem ganhado reconhecimento e se tornado uma técnica amplamente utilizada e bem aceita na literatura devido as suas vantagens ${ }^{3-6}$. Essa técnica está associada à redução do tempo de tratamento, dos custos e do número de intervenções cirúrgicas, além da preservação da altura e espessura óssea alveolar e a dimensão do tecido mole, vantagens que promovem a melhora no tratamento reabilitador e maior facilidade no planejamento cirúrgico para o implantodontista ${ }^{7,8}$.

No entanto, esta técnica pode ser um desafio quando se trata de implantes na região dos molares, visto que características clínicas como tamanho e altura do alvéolo podem dificultar a instalação dos implantes. Sendo assim, uma nova abordagem foi proposta por Rebele, Zuhr e Hurzeler ${ }^{9}$ (2013), onde publicaram uma série de casos clínicos em que foi realizado o preparo do leito implantar prévio a extração das raízes. A fresagem é realizada no centro do dente e somente após o fim do preparo as raízes são extraídas e o implante instalado.

O objetivo deste trabalho foi apresentar um caso clínico em que se utilizou a técnica de preparo do leito do implante prévio a extração das raízes como descrito por Rebele, Zuhr e Hurzeler $(2013)^{9}$, visando preservação da estrutura óssea adjacente, permitindo o correto posicionamento tridimensional do implante e garantindo todas as vantagens de implantes imediatos.

\section{RELATO DE CASO}

Paciente JNPS, 39 anos de idade, sexo masculino com queixa de coroa do dente 46 fraturada sem sintomatologia dolorosa. Ao exame clínico foi constatada a ausência do remanescente coronário, porém sem sinais de inflamação (Figura 1-A). Foi realizada radiografia panorâmica (Figura 1-B) e periapical (Figura 1-C) onde observamos material radiopaco sugestivo de tratamento endodôntico, sem presença de lesão periapical ou periodontal e amplo septo inter-radicular que favorece a instalação de implante imediato. 
Após apresentar as diferentes opções de tratamento, o paciente consentiu e assinou o termo de consentimento livre esclarecido (TCLE) para a instalação de implante imediato com preparo do leito do implante previamente à exodontia e posterior reabilitação com coroa metalocerâmica parafusada sobre implante.

Após a anestesia local foi realizado descolamento do tecido gengival com auxílio de uma lâmina de bisturi 15 e descolador do tipo Molt (Figura 1-D, Figura 1-E e Figura 1-F). Após o descolamento do tecido iniciou-se o preparo do leito do implante com a fresagem com broca lança na região do centro da raiz residual do dente 46 . Em seguida as demais fresagens foram realizadas com as brocas Titamax 2.0, piloto $2 / 3$ e Titamax 2.8, todas no comprimento de $9 \mathrm{~mm}$ no septo ósseo e $2 \mathrm{~mm}$ apical em relação à tábua óssea vestibular (Figura 2-A).

Após o preparo do leito do implante, a raiz residual foi extraída com auxílio de um periótomo visando a exodontia de forma atraumática a fim de preservar os tecidos adjacentes (Figura 2-B, Figura 2-C). Foi realizada a inspeção do alvéolo e o debridamento do local para remoção de tecido de granulação.

Ao final da exodontia, foi utilizado o paralelizador para avaliar a posição e angulação do implante e em seguida (Figura 2-D), instalado um implante imediato Cone Morse 3,75x9mm (Titamax CM Cortical - Neodent, Curitiba, Brasil) e obtido um torque final de $20 \mathrm{~N} / \mathrm{cm}$ (Figura 2E e 2-F). Na sequência, foi instalado um cicatrizador de 4,5 X 3,5 mm (Figura 3-A), sutura com fio nylon 5.0 e realizada uma radiografia panorâmica pós-cirúrgica (Figura 3-B). No pós-operatório foi orientada a utilização de digluconato de clorexidina a $0,12 \%$ por dez dias, anti-inflamatório e analgésico em caso de dor persistente.

Após 4 meses da instalação do implante imediato (Figura 3-C), foi instalado um pilar protético (Pilar CM - Neodent, Curitiba, Brasil) com altura de 2,5 mm (Figura 3-D) com torque de $32 \mathrm{~N} / \mathrm{cm}$. Uma coroa metalocerâmica foi instalada e realizado o selamento provisório com bastão de guta-percha aquecida. Foi realizada uma radiografia periapical para avaliar a instalação da coroa (Figura 3-E). Após uma semana foi conferido o torque do parafuso protético $(10 \mathrm{~N} / \mathrm{cm})$, ajuste oclusal e interproximal (Figura 3-F) e realizado o selamento definitivo com fita teflon e resina composta fotopolimerizável.

No retorno de 12 meses da instalação do implante foi observado clinicamente tecido gengival saudável, e exames radiográficos sem alterações apresentando neoformação óssea ao redor do implante.

\section{DISCUSSÃO}

Esse caso clinico apresentou o uso de uma técnica alternativa que facilita a instalação de implantes imediatos em regiões de bifurcações de molares. Esta abordagem facilita o posicionamento tridimensional do implante, preserva a estrutura óssea e permite uma maior previsibilidade no procedimento cirúrgico.

O preparo do leito do implante prévio a instalação de implantes em regiões de molares apresenta uma técnica alternativa que permite redução de custos e do tempo clínico por se tratar de implantação imediata, além de amenizar as dificuldades encontradas frente à instalação de implantes em regiões de bifurcações, como a falta de apoio para fresagem no centro do septo inter-radicular ${ }^{9-12}$.
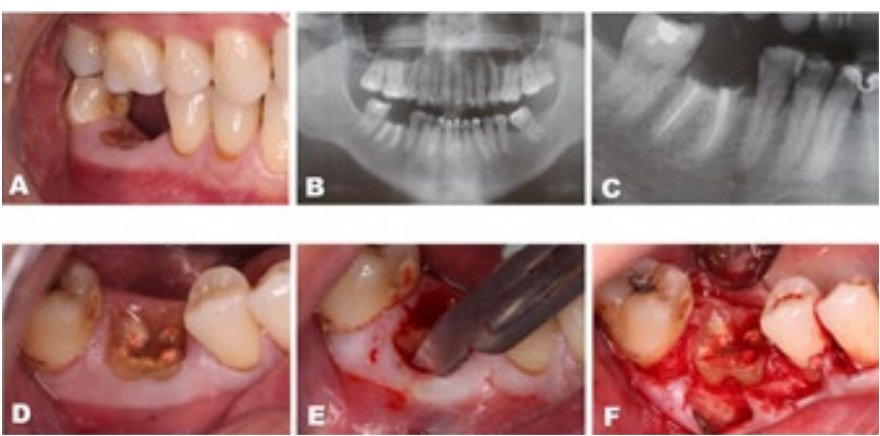

Figura 1- (A) Vista lateral da região do dente 46 sem remanescente coronário; (B) Radiografia panorâmica inicial; (C) radiografia periapical do dente 46; (D) Vista oclusal da região do dente 46 sem remanescente coronário; (E) Incisão circundando a raiz residual do dente 46; (F) Descolamento do tecido gengival da região a ser operada
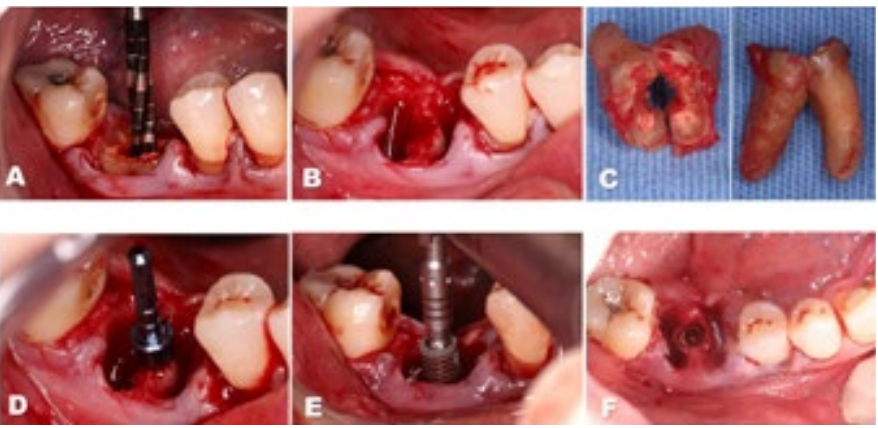

Figura 2 - (A) Broca 2.8 em fresagem no centro do dente 46 para o preparo do leito do implante; (B) Vista da região do dente 46 após o preparo do leito do implante e da extração das raízes residuais; (C) Vista das raízes do dente 46 após a exodontia com perfuração no centro em que foi realizado a fresagem; (D) Uso do paralelizador para avaliar a posição e angulação do implante; (E) Instalação do implante Cone Morse 3,75 x 9 mm; (F) Vista da região após instalação do implante
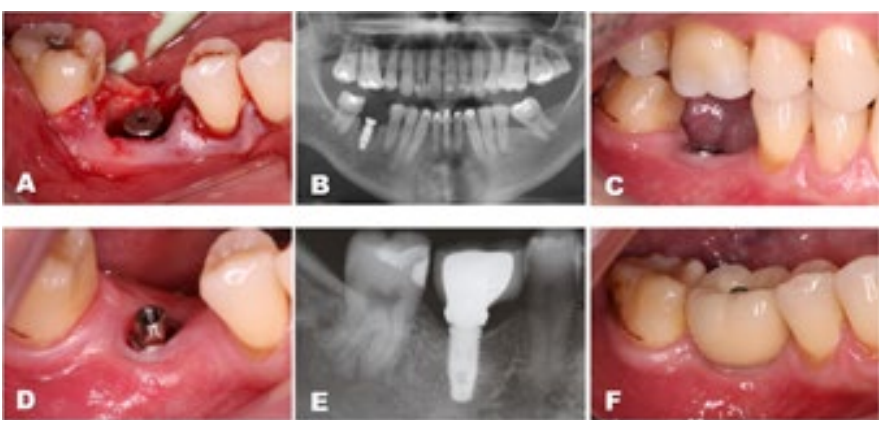

Figura 3 - (A) Instalação do cicatrizador; (B) Radiografia panorâmica após a instalação do implante; (C) Cicatrizador descoberto após 4 meses da instalação do implante; (D) Pilar protético instalado; (E) Radiografia periapical após 6 meses da instalação do implante; (F) Vista lateral da coroa após 2 meses da instalação

As vantagens desta técnica se assemelham as do implante imediato com a maior facilidade durante o preparo e instalação do implante. É necessária uma boa avaliação da condição periodontal prévia a cirurgia, além de brocas com um bom estado de conservação para que realizem o preparo sobre as raízes de forma adequada. Uma cuidadosa avaliação do leito cirúrgico deve ser realizada para que não fiquem resquícios da raiz perfurada ${ }^{9,13,14}$.

Ainda são necessários estudos em comparação com o protocolo convencional de implantes imediatos visando aprimorar a técnica e as suas indicações, assim como prever suas possíveis desvantagens e riscos para cada caso clínico. 


\section{CONCLUSÃO}

A técnica utilizada facilita o preparo do leito receptor e o posicionamento tridimensional ideal dos implantes em locais de extração com múltiplas raízes, além de diminuir o custo e o tempo de tratamento. Desta forma pode ser empregada em situações clínicas semelhantes e gerar resultados clínicos satisfatórios.

\section{REFERÊNCIAS}

01. Schulte W, Heimke G. The Tubingen immediate implant. Quintessenz. 1976; 27(6): 17-23.

02. Schulte W, Kleineikenscheidt H, Lindner K, Schar ER. The Tübingen immediate implant in clinical studies. Dtsch Zahnarztl Z. 1978; 33(5): 348-359.

03. Schropp L, Isidor F. Timing of implant placement relative to tooth extraction. J Oral Rehabil. 2008; 35(suppl. 1): 33-43.

04. Lazzara RJ. Immediate implant placement into extraction sites: Surgical and restorative advantages. Int J Periodontics Restorative Dent. 1989; 9(5):332-343.

05. Becker W, Goldstein M. Immediate implant placement: Treatment planning and surgical steps for successful outcome. Periodontol 2000. 2008; 47: 79-89.

06. Denissen HW, Kalk W. Preventive implantations. Int Dent J. 1991; 41(1):17-24.

07. Becker W, Becker BE. Guided tissue regeneration for implants placed into extraction sockets and for implant dehiscences: Surgical techniques and case report. Int J Periodontics Restorative Dent. 1990; 10(5): 376-391

08. Jyothi SG, Triveni MG, Mehta DS, Nandakumar K. Nandakumar. Evaluation of single-tooth replacement by an immediate implant covered with connective tissue graft as a biologic barrier. Journal of Indian Society of Periodontology. 2013;17(3): 354-360.

09. Rebele SF, Zuhr O, Hürzeler M. B. Pre-extractive interradicular implant bed preparation: case presentations of a novel approach to immediate implant placement at multirooted molar sites. Int J Periodontics Restorative Dent. 2013; 33(1):88-95.

10. Lang NP, Pun L, Lau KY, Li KY, Wong MC. A systematic review on survival and success rates of implants placed immediately into fresh extraction sockets after at least 1 year. Clin Oral Implants Res. 2012; 23(supp. 5): 9-66

11. Bhola M, Neely AL, Kolhatkar S. Immediate implant placement: Clinical decisions, advantages, and disadvantages. J Prosthodont. 2008; 17(7): 576-581.

12. Barzilay I. Immediate implants: their current status. Int J Prosthodont. 1993; 6(2):169-175.

13. Davarpanah M, Szmukler-Moncler S. Unconventional implant treatment: I. Implant placement in contact with ankylosed root fragments. A series of five case reports. Clin Oral Implants Res. 2009; 20(8): 851-856.

14. Barzilay I, Grazer GN,Iranpou B, Natiella JR. Immediate implantation of a pure titanium implant into an extraction socket: report of a pilot procedure. Int J Oral Maxillofac Implants. 1991; 6(3): 277-284.

\section{ABSTRACT}

Objective: to present a case report of immediate implant surgery in the region of an extensively damaged molar using an alternative osteotomy technique with bone drilling prior to root extraction. Materials and methods: in December 2017 JNPS, 39-years-old male patient, attended to the Faculty of Dentistry, complaining about a fractured tooth without pain symptoms. At clinical and radiographic exams, tooth \#46 was endodontically treated without coronal structure and wide inter-radicular septum, favoring the insertion of an immediate implant. Implant surgery was performed in February 2018 by drilling the implant bone site in the central region of the tooth prior to extraction. Then, the roots were extracted using minimally traumatic procedures, aiming to preserve the surrounding bone structure. A 3.75x9 mm morse taper implant (Titamax CM Cortical, Neodent,
Curitiba, Brazil) was inserted. The final insertion torque was 20 $\mathrm{N} / \mathrm{cm}$ was obtained and a healing cap was installed for a onestage surgical procedure. After 4 months, a $2.5 \mathrm{~mm}$ height prosthetic abutment (Pilar CM - Neodent, Curitiba, Brazil) was installed and in the following appointments the procedures for fabrication of a metalceramic crown were performed. Results: in the 12-month follow-up, clinical and radiographic aspects of normality were observed, and patient reported satisfaction with the treatment. Conclusion: the technique used in this clinical case facilitated the bone preparation for implant insertion, preserving bone structure for a favorable implant stability, and may be recommended for similar clinical situations.

KEYWORDS: Dental implant; Dental prosthesis; Osteotomy.

\section{AUTOR PARA CORRESPONDÊNCIA}

Sara Cristina de Araújo

Av. Universitária, s/n - Setor Leste Universitário, Goiânia - GO.

E-mail: odontosaraa@gmail.com 